\title{
The Influence of Reputation on Consumer Purchasing Behavior
}

\author{
Li-Wei Lin ${ }^{1}$, Meng-yao Zhang ${ }^{* 2}$, Yun-Han Zhang ${ }^{3}$ \\ 1 The School of International Business, Zhejiang Yuexiu University, No.428 Kuaiji Road, YueCheng District, \\ Shaoxing312000, China \\ *2 Zhejiang Institute of Mechanical \& Electrical Engineering \\ 3 Zhejiang University of Finance and Economics Dongfang College, Zhejiang China.
}

\begin{abstract}
This study created a new model to explore the impact of social network word of mouth on the credibility of the website platform factors. This model contains three assumptions, including website trust, consumer repurchase, and timely response from website customer service. This structure has been discussed a lot in e-commerce literature. This hypothesis is explored through empirical research testing. The data of this study is a questionnaire survey of consumers on a platform of a case company. The data is collected from 100 consumers in 2014.The results show that the word-of-mouth information and online immediacy have a relevant influence and help on consumers' re-purchase behavior. At the same time, the results show that there is a good interaction between online word-of-mouth and online immediacy. The results of this study provide useful insights into how to enhance consumers' perception of online word-of-mouth messages and online immediacy in order to enhance the behavioral impact on consumers' repurchase intentions.
\end{abstract}

Keywords: website word of mouth message, trust, consumer repurchase intention, online immediacy

\section{Introduction}

\subsection{Research background and motivation}

More and more advanced computer technology, in addition to computers can use WIFI to access the Internet, smart phones can also use 3G all-you-can-eat Internet everywhere, now Taiwan area is also building 5G online base station. That is also the development of the Internet, so that more enterprises into e-commerce, coupled with the government's financial regulatory commission to launch a new policy third-party payment law is expected to pass by the end of 2021, the development of E-commerce in Taiwan will be more perfect.

A certain company is located in Taiwan. It started to sell clothing and clothing accessories. With the expansion of its business scale, it began to sell comprehensive commodities (including books, household products, 3C products and food products), providing product price discounts in terms of business strategy, so that consumers could receive goods quickly when placing orders. On the other hand, in terms of Internet marketing strategy, the 
case company quickly attracted more popularity by advertising exposure through well-known portal websites in Taiwan, participating in advertising sponsorship activities of sports events in Taiwan, and cooperating with mobile apps. This study is intended to be a model for other industries in Taiwan through the Internet marketing strategy and customer satisfaction re-purchase rate of a particular company.

On the other hand, in the software part, when consumers consume on the websites, they add SSL encryption protection on the website software when they fill in the membership, hoping to make consumers shop safely online and avoid being stolen by hackers, so that consumers can feel at ease when shopping. To establish a good platform, the website reputation on the consumer purchase behavior of the influence of one of the motivations.

The development of the Internet and the influence of website information transmission on consumer shopping are the second motivation of this study.

Online customer service and after-sales service are key factors for customer service personnel to serve consumers, just like the waiters in physical stores who greet customers with smiles and friendly service attitude. The Internet customer service staff may not be able to satisfy consumers face to face, but can only talk online and notify them by telephone in a virtual way. How to make consumers feel satisfaction and value of the service, and then make consumers willing to continue to buy online is the third motivation of this study.

\subsection{Research purpose}

The purpose of this study is to explore the business model strategy and customer satisfaction of e-commerce network. This study is expected to have a deeper understanding of an e-commerce platform, understand the factors affecting the establishment of e-commerce platform business strategy and customer satisfaction, and then put forward problems conducive to the positioning and development of an e-commerce case company. The purposes of this study are as follows:

(1)Understand how to build e-commerce platform to bring business opportunities and market share.

(2)Understand the customer satisfaction of a company after sales.

(3) Understand the brand benefits of a company's online marketing, and understand whether the online marketing strategy is translating customer traffic into purchase rates.

(4)Explore the impact of consumers' interaction with websites and cognitive risk on trust.

(5)Explore the influence of consumption of different age groups on consumption power.

\subsection{Research scope and limitations}

\subsubsection{Research scope}

In recent years, Internet marketing activities are very hot, many enterprises in order to let their brand awareness 
exposure, through the exposure of various websites to increase awareness. Marketing Strategy Many companies will design a different theme for their marketing strategy each quarter of the year. The main purpose is to impress consumers with their brand identity. This study is aimed at a case company engaged in Internet marketing activities, observe whether the effect of Internet marketing strategy on customer purchase rate, to analyze its two-way relationship.

\subsubsection{The limit}

(1) Due to the influence of human resources, material resources, time, budget and other factors, this study only focuses on the customers who consume on the e-commerce platform of a certain company. Therefore, special caution should be exercised in the inference and interpretation of the research results.

(2) This study adopts the questionnaire survey method, and the questionnaire design adopts different market conditions in each quarter of operation, and constantly adjusts the design; Although there are references to foreign literature, there are some imperfections in the design of the questionnaire. When consumers fill in the questionnaire, they may be affected by the sensitivity of the questionnaire questions or consumer awareness, leading to errors in the results.

\subsection{Research process}

This study discusses e-commerce platform companies based on the study of e-commerce business model. The study will follow the following process, as shown in Figure 1:

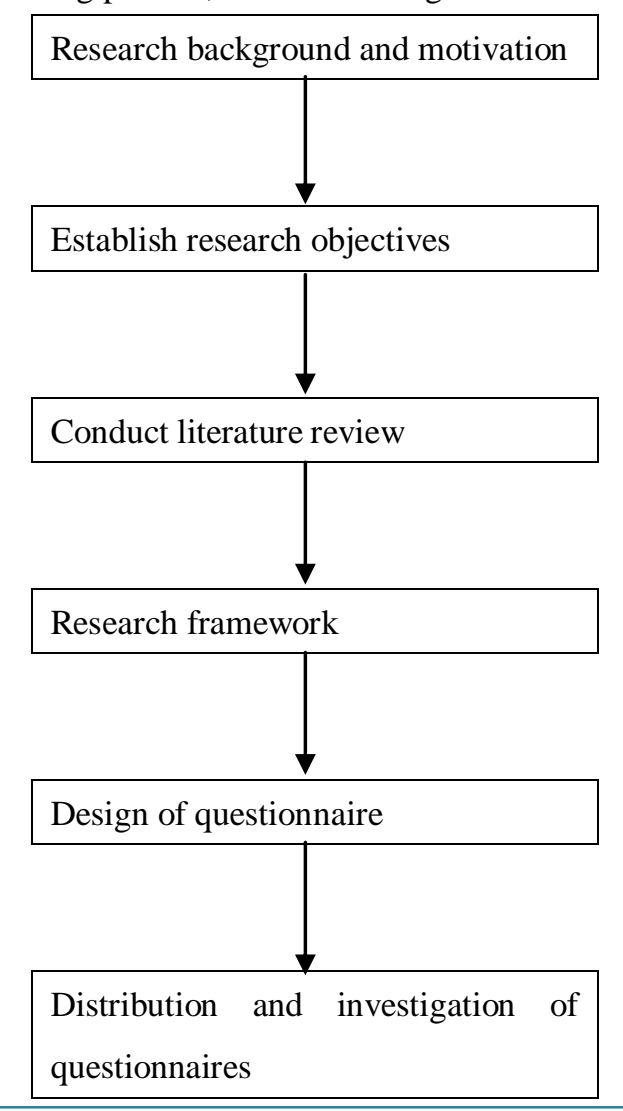




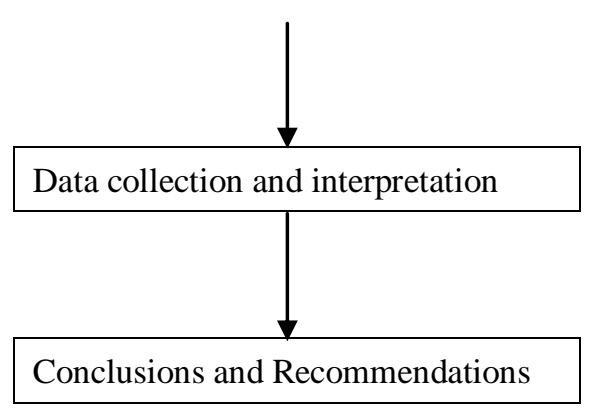

Figure 1 Research flow chart

\section{Literature review}

\subsection{Internet marketing related literature}

Network marketing this term concept, now our life occupies a large proportion, as long as open the computer to surf the Internet, in different websites will see network marketing advertising; Or use mobile Internet, you will see a lot of communication software advertising, such online marketing has gradually replaced the traditional bricks-and-mortar advertising. Nowadays, the most popular APP is to download through the mobile phone, so that consumers can get some shopping discounts, such communication software has changed consumers' shopping mode.

\subsubsection{Definition of Internet marketing}

What is Internet marketing, many Internet marketing can also be called virtual marketing, mainly through the spread of the Internet speed, a large number of products introduced to consumers, prompting consumers to finally buy. The definition of Internet marketing, some scholars attach importance to Internet technology, while others attach importance to Internet marketing, is explained as follows:

Davids(1994) defined Internet marketing as: Internet marketing is to sell products and services to users who use Internet and commercial online services, and cooperate with the company's overall marketing plan to attract users through the online system, and use the Internet to obtain information and buy products. Hanson(2000) believes that Internet marketing refers to the marketing activities carried out by individuals who use the Internet to obtain digital goods in terms of whether an enterprise has marketing. Internet technology and economy and other Internet marketing elements. Liu et al. (2001) argue that Internet marketing uses the Internet and the information services built on it as a tool to achieve virtual Internet marketing. The Internet as a communication medium, and meet its lowest cost needs. Wang Zhiping (2002) believes that Internet marketing is a marketing method to achieve marketing goals through network technology, communication and digital switching technology.

\subsubsection{Internet and Internet marketing features}

Peterson et al. (1997) believe that the characteristics of the Internet are: 
(1) Storage of large amounts of available information at very low cost in different virtual locations.

(2) use low-cost search and integration of such information.

(3) Provide information and interaction according to consumer needs.

Hanson(2000) believes that the Internet has twenty-four hours and can be connected to the Internet anytime and anywhere.

Kalakita et al.(1999) believed that the biggest difference between the Internet and general media lies in its high interactivity, so the main characteristics of Internet marketing are as follows:

(1) Information: information openness is the main feature of the Internet. If the layout and information designed by the Internet meet the needs of consumers, it can attract fixed customer groups.

(2) Customer information archival: E-commerce network operation can establish archives through the customer information of consumers, so that consumers can quickly accept different information and meet the needs of different consumers.

(3) Interaction: Online customer service can interact with consumers, and provide services for consumers through their problems, so that consumers can have fun shopping through the platform.

\subsubsection{Types of Internet marketing}

Lin Junya (2004) believes that Internet marketing helps enterprises set up commercial websites, release product information on the Internet, and attract consumers' attention by releasing new products and promotional discounts on the Internet platform from time to time. Internet marketing can be divided into four types according to different characteristics of products and Internet services:

(1) Online instant trading: through shopping cart, the transaction process will appear when consumers shop on the online line. After consumers place an order, the system will show the order number or inform them by sending emails and mobile phone messages.

(2) Logistics: after the consumer places the order, the manufacturer sends it to the consumer through logistics.

\subsubsection{Advantages of Internet marketing innovation}

Kolter,P.(2008) believes that traditional marketing management emphasizes product, price, promotion and channel (4P) product combination, while modern marketing management stresses consumer feedback, cost, delivery speed and communication. In practice, there is a lack of communication between customers and enterprises, and there is a lack of appropriate communication channels. Through network marketing tools, online customer service or E-mail, online message, enterprises can use network marketing tools to reduce marketing costs, such a two-way communication mode, can make network marketing more efficient to find their own customer group. The advantages of Internet marketing are as follows:

(1) Network marketing is not limited by time, network marketing is not limited by the time difference between countries, people will come to visit the store all the time. 
(2) Network marketing customer consumption shopping operation privacy protection: customers in the process of purchasing products, shopping security process will be SSL encryption to ensure that consumers in the shopping data will not be damaged by hackers, to secure shopping.

(3) No regional restrictions: Network marketing can provide rich information and relevant information to customers in different regions, consumers can compare on the website platform and make purchasing decisions.

(4) Network marketing market in the next 20 years the most dynamic sales way: enterprises can through the network marketing way, to create brand value increase, and constantly growing turnover increase, so network marketing tools become the most dynamic sales way in the next 20 years.

\subsection{Consumer satisfaction related literature}

Enterprise Internet marketing strategy has a great impact on consumer satisfaction, why consumers want to buy again and after the purchase is a major factor. As for the definition of consumer satisfaction, scholars have also put forward various opinions.

\subsubsection{Definition of consumer satisfaction}

Andrews and Withey(1976) believe that satisfaction is a function formed by the original criteria and several cognitive differences from internal reference points and external reality. The so-called consumer satisfaction refers to the feeling and satisfaction experience of consumers after using the product and the cognitive evaluation of the comparison with the expectation of the product they have not purchased before. If the actual performance exceeds the expectation, consumers will be satisfied. Miller(1977) pointed out that consumer satisfaction is generated by the degree of consumer expectation and cognitive effect. Oliver(1981) believed that satisfaction refers to the fact that consumers develop an attitude based on expectations with specific consumption experience, and then adjust their attitude according to whether they are satisfied with their consumption experience. Oliver and Desaarbo(1988) believed that service quality was a leading variable of consumer satisfaction.

Hernon, Nitecki, and Altman(1999) believed that consumer satisfaction should include the satisfaction of direct contacts, overall service satisfaction and service personnel satisfaction. Kristensen, Martensen\&Gronoldt(2002) proposed that consumer satisfaction is the evaluation reaction of consumers on product purchase and experience, which comes from the comparison between expectations and gains.

\subsubsection{Consumer satisfaction model}

Fornell(1992) studied more than 130 companies in 32 large industries on national consumer satisfaction indicators. They established a set of systematic and long-term national consumer satisfaction indicators, whose model includes the following five aspects:

(I) Satisfaction degree: the overall satisfaction degree, the degree of meeting expectations, and the gap between ideals. 
(2) desire before purchase: consumer expectations of the product.

(3) Post-purchase feeling and performance: whether consumers have a corresponding purchase value for product quality and price after purchase.

(4) Complaints: the number of complaints from consumers about sales staff.

(5) loyalty: price tolerance and repurchase willingness.

Oliver and Desarjo(1988) regarded consumer satisfaction as a way of evaluating the relationship between consumers' anticipation and cognitive performance. Therefore, the customer satisfaction model is expressed in a functional form, and it is considered that customer satisfaction $=\mathrm{F}$ (expectation before purchase, performance after purchase)

\subsubsection{Customer satisfaction and loyalty}

For enterprises, it has become an important task to maintain the old consumers. In order to achieve this goal, most enterprises will maintain the old consumers and devote themselves to the loyalty of consumers and products. What is consumer loyalty. Bhote(1996) believes that the so-called consumer loyalty refers to a series of activities in which consumers are satisfied with the products and services of an enterprise, so that consumers are willing to promote the products of the enterprise, say good things about the products after use in front of others, and create positive word-of-mouth. Jones and Sasser(1995) pointed out that consumer loyalty is the willingness of consumers to repurchase a particular product or service. In addition, there are three ways to measure consumer loyalty: consumers repurchase intention and consumer basic behavior, including the last purchase time, purchase times, purchase quantity and derivative behavior.

\section{Research methods}

According to the results of the study purpose and literature review, this study put forward the research framework and the research hypothesis, and in one case: an actual company enterprise Internet marketing strategy and the study of the customer satisfaction questionnaire as a test tool, take the questionnaire survey to collect data, to perform statistical analysis, to verify the hypothesis of this study. The main contents of this chapter include research framework and hypotheses, measurement tools, sampling methods, data processing and statistical methods. 


\subsection{Research Framework Diagram}

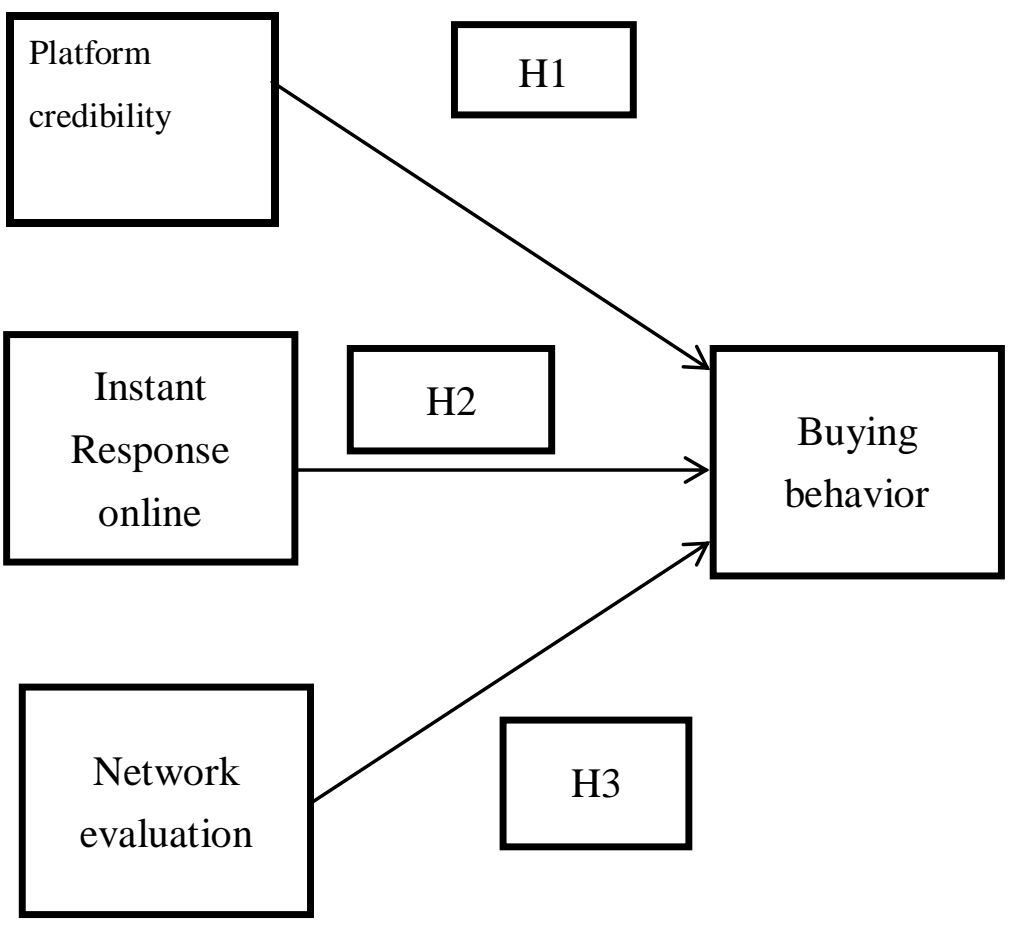

\subsection{Selection of research methods}

This study focuses on the effect of reputation on consumer behavior. Therefore, in the selection of research methods, in order to clarify the relationship between causal variables, this study decided to adopt the laboratory experiment method with the best internal validity.

Although the external validity of the laboratory method is low, the internal validity can accurately explore the correlation between the independent variable and dependent variable concerned in the research by manipulating the variables. Therefore, the laboratory experiment method was used in this study to reduce the occurrence of errors.

In order to meet the theme of this study, this study investigates the influence of platform reputation on consumers' purchasing behavior through social network and online questionnaire survey.

\subsection{Research hypothesis}

Hypothesis 1: Platform reputation has a significant impact on consumers' purchasing behavior.

Hypothesis 2: Online instant response has a significant impact on consumers' repurchase intention.

Hypothesis 3: Online word-of-mouth messages have a significant impact on consumers' purchasing behavior. 


\subsection{Experiment design}

The questionnaire was measured by Likert five-point scale, and 1-5 points were given according to options such as "strongly agree", "disagree", "common", "agree" and "strongly agree". Respondents answered the questionnaire according to their subjective cognition.

This experiment was conducted in Starbucks, and the experimental process included: randomization of the experimental group, operation instructions before the experiment, and questionnaire filling. The experimental process takes about 30 minutes.

\section{References}

[1] David, M., “The Interactive Evolution”, Journal of Strategic Marketing, vol.12, 1994, pp.52-55

[2] Hanson, W., "Internet Marketing”, Mason,OH: South-Western College, 2000.

[3] Kalakota, Ravi and Marcia Robinson, "E-business - Roadmap for Success”, New York: Addison-Wesley, 1999.

[4] Lin jun-ya (2004), Principle of Manufacturer Integration, Taipei: Huatai Cultural Enterprise Co., LTD.

[5] Stuart, D. H. (2001), Strategic Management: Conceptual Framework and Analytical Methods, Chi Sheng Press, Taipei.

[6] Wangzhiping (2002), Introduction to Internet Marketing. Taipei: QuanHua.

[7] XuHaoqian (2009), The Effect of employee job satisfaction on customer satisfaction: Emotional labor and emotional infection,Master thesis, Institute of International Enterprise, Taiwan University.

[8] XieSongyi (2006), Sustainable management philosophy and manpower selection and training in financial industry research,Ph. D. dissertation in industrial engineering and management, National Jiaotong University.

[9] YangYating (2010), Customer satisfaction and Loyalty in Online Group buying and its Preconditions,NationalChengchi University master of Management program master thesis. 